\title{
Risk assessment: method and case study for traffic projects
}

\author{
Xin $\mathrm{Yu}^{1}\left({ }^{1} \cdot\right.$ Panos D. Prevedouros ${ }^{2}$
}

Received: 15 June 2016/Revised: 14 July 2017/ Accepted: 17 July 2017/Published online: 29 July 2017

(c) The Author(s) 2017. This article is an open access publication

\begin{abstract}
A comprehensive project evaluation and decision-making method considering multiple objectives, stakeholders, and attributes of proposed traffic treatments is inherently complicated. Although individual techniques in evaluating operations, safety, economic, and stakeholder objectives are available, a practical method that integrates all these risk factors and their uncertainties into a multiattribute decision-making tool is absent. A three-level project decision-making process was developed to model and assess multiple-attribute risk in a proposed traffic treatment from the perspective of multiple stakeholders. The direct benefits from reducing delay and safety risk (basic objectives of traffic treatments) are computed in Level 1 with established methods. Feasibility and performance analysis in Level 2 examine site-specific constraints and conduct detailed performance analysis using advanced analysis tools. In Level 3, this paper introduces an innovative and integrated multiple attributes evaluation process under fuzziness and uncertainty (MAFU) process for evaluation and decision-making. The MAFU is a comprehensive and systematic assessment and decision-making procedure that can assess the magnitudes of project performance and to integrate conflicting interests and tradeoffs among stakeholders. A case study illustrates the
\end{abstract}

$\mathrm{Xin} \mathrm{Yu}$

alyx.yu@gmail.com

Panos D. Prevedouros

pdp@hawaii.edu

1 KPMG LLP, 1601 Market Street, Philadelphia, PA 19128, USA

2 Department of Civil and Environmental Engineering, University of Hawaii at Manoa, 2540 Dole Street, 383, Honolulu, HI 96822, USA application of MAFU for the selection of a traffic alternative involving several evaluation attributes and stakeholders. Results show that the MAFU produced the smallest variance for each alternative. With traditional cost-benefit evaluation methods, the uncertainty associated with performance of a traffic project in terms of operation, safety, environmental impacts, etc., is unrestricted and cumulative. Therefore, a reliable multi-attribute evaluation of complex traffic projects should not be made with conventional costbenefit analysis alone but with a process like MAFU.

Keywords Risk assessment · Uncertainty · Traffic project . Monte Carlo Simulation · Decision-making

\section{Introduction}

Traffic improvement projects are designed to maximize traffic performance and safety, and minimize costs, energy consumption and other adverse environmental impacts. Traffic projects in dense urban areas generate many and potentially big impacts because they affect commuting and transit patterns, abutting land uses and multilayered utilities. A trade-off decision-making process is more appropriate for traffic projects involving large-scale development and capital investment, because of

1. multiple and sometimes conflicting objectives (e.g., simpler signal phasing may be more efficient but has more conflicting movements that raise accident risk),

2. conflicting interests among stakeholders (e.g., removal of a parking lane improves traffic flow but may reduce patronage for local businesses), and

3. uncertainty in modeling and forecasting project performance. 
The existence of multiple project objectives, the conflicts of stakeholder perceptions and desires, and the uncertainty in project performance predictions necessitate a comprehensive and integrated approach to evaluate and select the best project alternative.

Although conventional traffic project evaluation and decision-making methods, such as cost-benefit analysis provides a set of values that are useful to determine the feasibility of a project from a static standpoint, Federal Highway Administration (FHWA) recommends that the full range of reasonable alternatives and their effects need to be considered [1]. Typical methods make fixed value assumptions of non-monetary variables (e.g., travel time, safety and noise) [2], ignore stakeholder variations of alternatives and their attributes [2], disregard information about the probabilistic distribution and uncertainty ranges of evaluation criteria [3], and aggregate certain and uncertain costs and benefits on a common scale [3]. Also there are concerns that they have a myopic focus on only a single stakeholder or a few stakeholders sharing similar interests, e.g., the traffic agency and the motorists.

Conventional project evaluation methods such as the surface transportation efficiency analysis module (STEAM) [4] can only be applied if all the major effects of a project are assessed in monetary terms and the stakeholders have common and consistent interests. Neither condition is realistic. Many impacts and attributes do not lend themselves to monetization, and stakeholders have conflicting objectives. The evaluation of large traffic projects is manifold, politically controlled and may include heavy public involvement. Technical decisions cannot be made without considering the best balance between conflicting interests.

The reduction of a multi-criteria assessment into a single net aggregated benefit masks some of the important attributes and may cause large inaccuracies. A multiple attributes evaluation process under fuzziness and uncertainty (MAFU for short) was designed to address these limitations. It is a disaggregate project evaluation method that integrates stakeholder trade-offs with the performance of alternatives while explicitly recognizing both the uncertainty of variables and the risk disposition of decision makers.

\section{Literature review}

Most of the past research has focused on capturing a portion of the uncertainties: either the uncertainty in project performance analysis or the uncertainty in project decisionmaking and stakeholder trade-offs. There is a vast amount of probability-based uncertainty and risk analysis. This brief review presents articles with direct connections to the MAFU method.
Bayarri et al. [5] assessed the uncertainties in a traffic simulation modeling arising from multiple sources: randomness in the simulator, statistical variability in estimating and calibrating input parameters, inaccurate data and model discrepancy. Ji and Prevedouros [6] introduced a probabilistic method to estimate control delay and level of service (LOS) with mean values, standard deviations, confidence intervals and distribution of delays. Li and Sinha [7] developed a multicriteria highway programming algorithm incorporating risk and uncertainty in asset management with asset valuation, performance modeling and marginal benefit analysis.

Uncertainty and trade-off analysis are also highlighted in recent research on decision-making process in transportation engineering and related domains. Zimmermann [8] introduced several operations research principles to help select the most appropriate method for solving a specific multi-criteria decision-making in ill-structured situations by using the analytic hierarchy process (AHP). Sjoerd and Kwakernaak [9] explored the application of fuzzy set theory to solve multiple-attribute decision problems under uncertainty and proposed the concept of membership level to fuzzify the inherent uncertainty of preference (ratings or weights) and to quantify the uncertainty of ratings or weights among different attributes or stakeholders. Arslan [10] developed a decision support model that considers public opinion in forming transportation policy or selecting transportation projects by using fuzzy logic and AHP. Bandte's joint probabilistic decision-making technique can account for the uncertain values of uncontrollable variables because of its ability to transform disparate objectives into a single figure of merit [11]. Ross et al. [12] expanded this technique into a multi-attribute tradespace exploration method to capture decision maker preferences and use them to generate and evaluate a multitude of space system designs. Nickel [13] further extended it to address multiple stakeholder structure and several cost types in transportation system analysis and highlighted the application of tradespace exploration in determining trade-offs between alternatives by providing expected benefits, variability, and patron optimal values. Using multi-attribute utility theory for the aggregation of preferences to create a common metric for evaluation, these techniques provide a common metric that can be easily communicated throughout the design and enables the analyst to discover better value designs for multiple stakeholders $[12,13]$.

\section{Methodology}

As shown in Fig. 1, the methodology progresses through three levels arranged in order of complexity, from planning and screening (Level 1) to site-specific feasibility and traffic study (Level 2) and to decision-making and final 


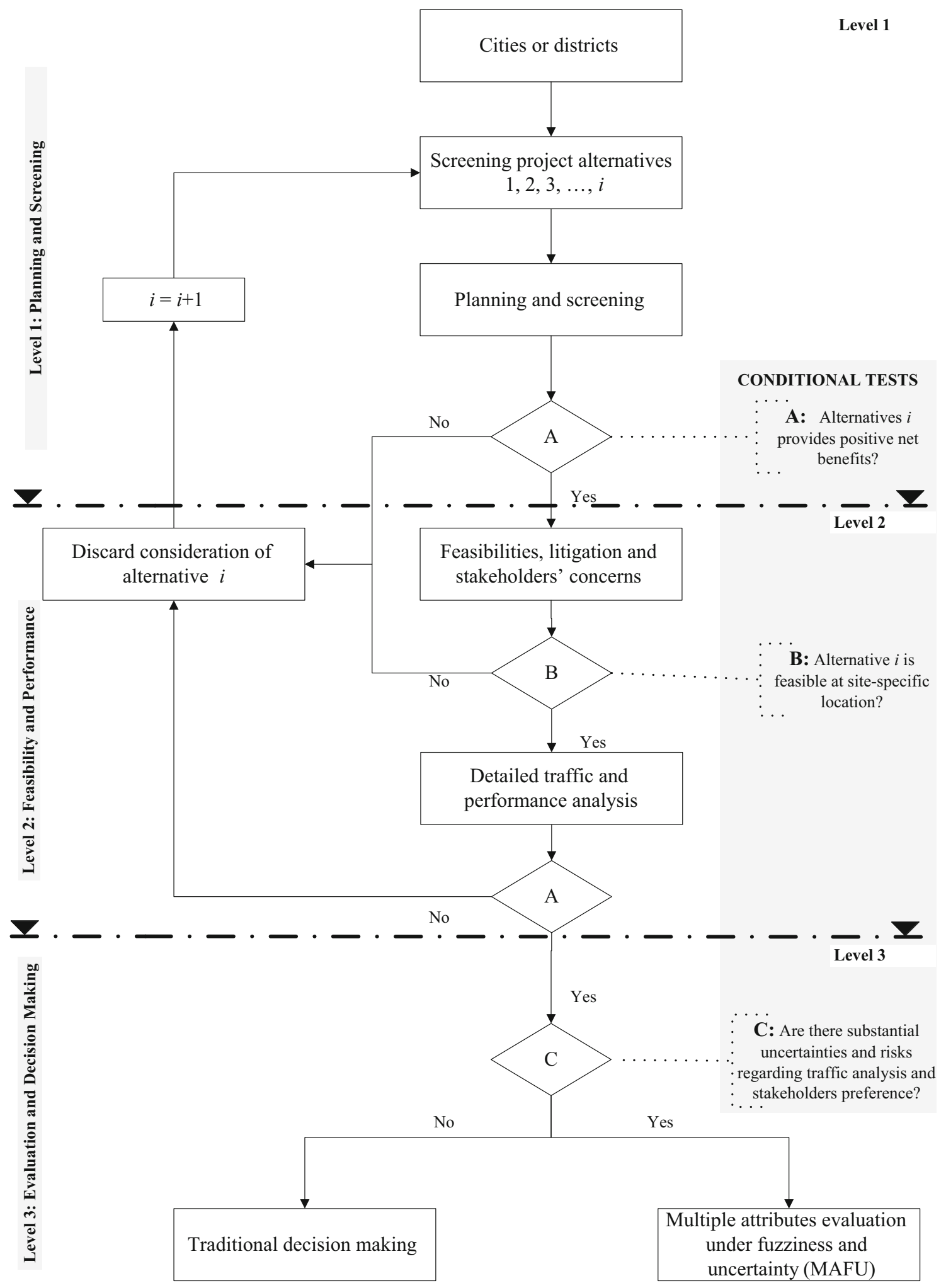

Fig. 1 Methodology framework

selection (Level 3). Three conditional tests move the process through the sequence of levels:

A. Does the alternative provide positive net benefits?
B. Is the alternative feasible at the specific location?

C. Are there substantial risks regarding the traffic analysis and stakeholder preferences? 
Level 1-Planning and Screening maximizes the use of standard, agency-approved methods to minimize requirements and to expedite the screening of multiple alternatives. This level produces fundamental technical and economic results, including preliminary project-wide operational, safety and cost-benefit outcomes. Traffic operations are addressed primarily using the Highway Capacity Manual (HCM) [14]. Safety conditions are evaluated using the Highway Safety Manual (HSM) [15]. A basic cost-benefit analysis is conducted using the user benefit analysis (UBA), typically referred to as the AASHTO Red Book [16].

Level 2-Feasibility and Performance examines the construction, budget and local and legal constraints of each alternative to verify its applicability. This level includes (i) the identification of project objectives and stakeholder concerns, project budgeting and scheduling, and construction impacts assessments and (ii) detailed traffic and performance analysis including traffic, environmental and other impacts analysis on adjacent intersections, roadways, and surrounding communities within a defined influence area. This level generates the performance attributes and their indicators used in MAFU at Level 3.

Levels 1 and 2 are integrated and comprehensive versions of typical steps used in traditional project evaluation consisting of various engineering studies and filter out infeasible alternatives. Level 1 and 2 analyses are detailed elsewhere [17]. The focus of this paper is the MAFU process conducted in Level 3.

MAFU is a multi-attribute, multi-criterion and multiobjective evaluation and decision-making process employing fuzzy mathematics to capture the trade-offs of stakeholder preferences, utility theory to describe risk sensitivity, and probabilistic approach to model criteria uncertainties. Monte Carlo simulation (MCS) and probabilistic methods are applied for capturing the variety of performance measures and examining the confidence level and the robustness of the final selection. Multiple-attribute utility theory with sampling-based replication across the design variable enumeration range is employed to generate a tradespace for determining the optimal solution and assessing the trade-offs. The term "tradespace" comes from an MIT-based study on developing multi-attribute tradespace exploration for aerospace applications [2]. It is an abbreviation of trade-off space, which is a graphical representation and database of supporting data and mathematical models of all possible solutions to an evaluation problem.

Although a full 3-level analysis is recommended for large-scale and multiple stakeholder projects, each level can lead to decision-making depending on the characteristics of the project [17]. The basic project characteristics that determine the need for MAFU are
- considerable uncertainty regarding the estimation of performance indicators,

- multiple stakeholders with conflicting interests in their expectations,

- changes in assumptions that result in significant variations in the ranking of alternatives.

\section{MAFU}

The MAFU process has five stages: initiation, weighting, scaling with risk and uncertainty, combination and decision, as shown in Fig. 2. Initiation frames the project, alternatives and stakeholders. Weighting assesses how decision makers attach a relative level of importance to each criterion. Scaling converts the performance measures of effectiveness (MOEs) to commensurable units and introduces the uncertainty of major inputs and the decision makers' risk perspective. Combination accounts for conflicting interests among various stakeholders. The mathematical tools employed at each step are detailed below.

\subsection{Initiation}

The initiation stage identifies project objectives, affected interest groups and project alternatives. For each performance attribute in Table 1, one or more performance MOEs can be selected to represent the extent to which the project objectives are achieved with the implementation of a project alternative. Operations and safety are the main concerns of most traffic projects, but there has been increasing consideration of energy, environment and accessibility.

\subsection{Weighting}

The assignment (explicit or implicit) of weights to performance MOEs for each attribute is one of the key steps and should be approached carefully, because weights may bias the selection of alternatives. Performance attributes have one or several MOEs; e.g., traffic delay, queue length and number of stops are MOEs of traffic operation performance. The MOEs selected for one performance attribute should be independent of each other. If multiple MOEs are defined for one attribute, then an expert panel or Delphi technique [18] is recommended to establish relative weights for them. Most large urban areas have sufficient local reservoirs of relevant expertise. In the case of traffic projects, experts may be selected form the city and state department of transportation (DOT), the metropolitan planning organization (MPO), and local engineering chapters and universities. 


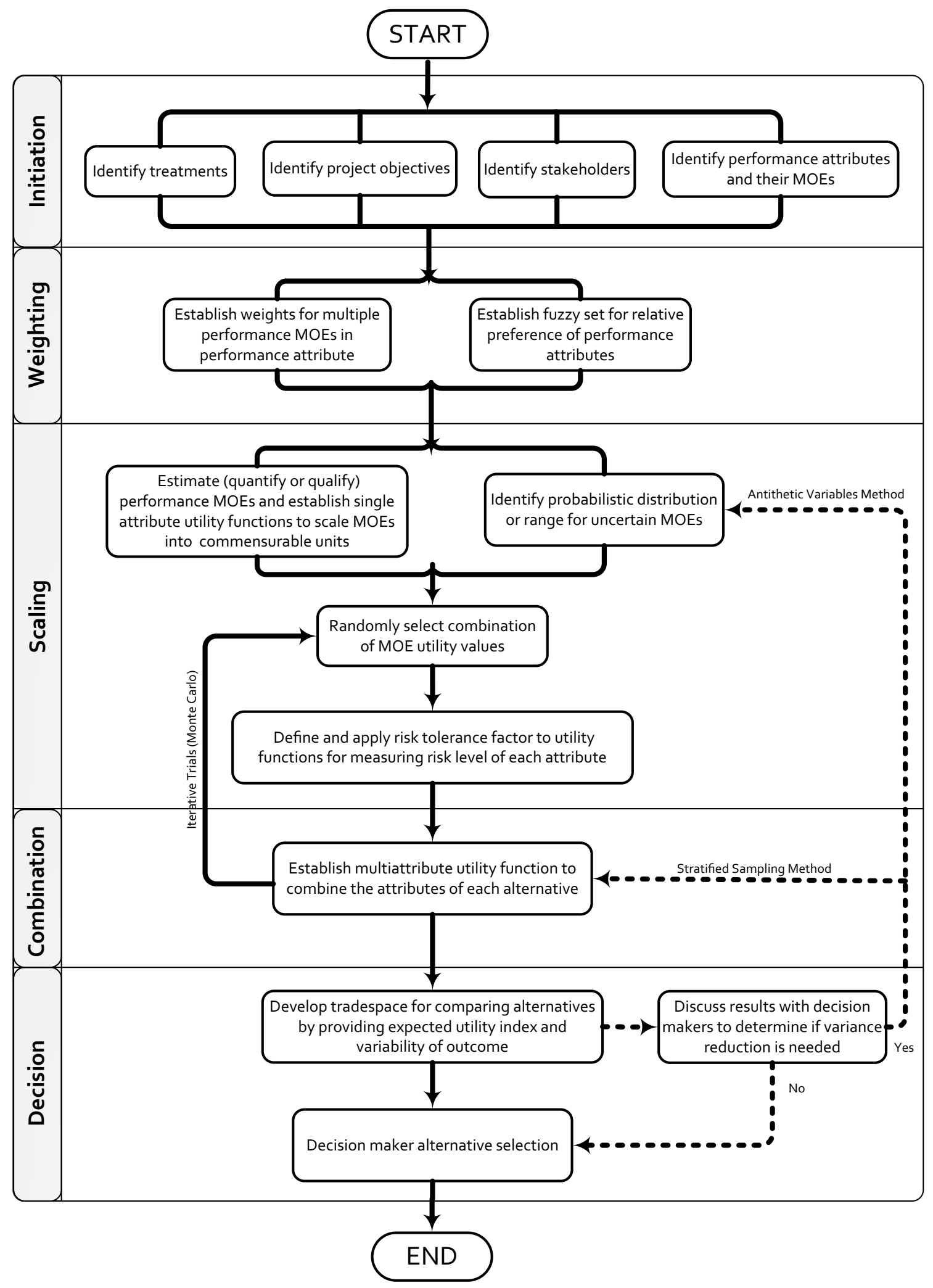

Fig. 2 Flowchart of MAFU 
Table 1 Performance attributes and corresponding MOEs

\begin{tabular}{|c|c|c|}
\hline $\begin{array}{l}\text { Performance } \\
\text { attributes }\end{array}$ & MOEs & Description \\
\hline \multirow[t]{4}{*}{ Operation } & Average vehicle delay & Average vehicle delay for all entering vehicles (usually used to define LOS) \\
\hline & Number of vehicles stopped & Number or proportion of entering vehicles that are required to stop due to vehicles \\
\hline & $95 \%$ Queue length & Total length of the queues for all approaches at the $95 \%$ confidence level \\
\hline & Volume-to-capacity $(V / C)$ ratio & Amount of capacity that is consumed by the current traffic loading \\
\hline \multirow[t]{4}{*}{ Safety } & Crash rate and severity & $\begin{array}{l}\text { The number and severity of crashes (historical or predicted) involving cars, trucks, } \\
\text { animals, bicycles and pedestrians }\end{array}$ \\
\hline & $\begin{array}{l}\text { Crash rate per } 100 \text { million vehicle } \\
\text { miles travelled }\end{array}$ & $\begin{array}{l}\text { Average fatal, injury and Property Damage Only (PDO) crash frequency every } 100 \\
\text { million vehicle miles travelled }\end{array}$ \\
\hline & $\begin{array}{l}\text { Number of alcohol or drug related } \\
\text { accidents }\end{array}$ & $\begin{array}{l}\text { Number of fatalities, injuries and PDO in crashes involving a driver or motorcycle } \\
\text { operator with consumption of alcohol or drugs }\end{array}$ \\
\hline & Safety behavior measure & $\begin{array}{l}\text { Such as observed seat belt use for passenger vehicles and number of speeding citations } \\
\text { issued }\end{array}$ \\
\hline \multirow[t]{4}{*}{ Energy } & Fuel usage & Fuel used (gallons) of all entering and leaving vehicles within the road network \\
\hline & Modal trips & Number of Transit and walk/bike trips for entire study area \\
\hline & Mode choice & Usage of high energy efficiency or alternative energy vehicles \\
\hline & Duration of truck engine idling & $\begin{array}{l}\text { Extra energy consumption of heavy vehicles during the congested or waiting period due to } \\
\text { engine idling }\end{array}$ \\
\hline \multirow[t]{4}{*}{ Environment } & Vehicle emissions & Change in emissions by pollutant and by vehicle type \\
\hline & Greenhouse gas emissions & Change in emissions of greenhouse gas by vehicle type \\
\hline & Release of harmful chemicals & $\begin{array}{l}\text { The amount of hazardous chemicals and wastes to the road user, residential area and the } \\
\text { entire environment }\end{array}$ \\
\hline & Noise level & The noise level generated by traffic and affected area and population \\
\hline \multirow[t]{3}{*}{ Accessibility } & Average travel time & Average travel times and distances (by mode) to specific locations within influence area \\
\hline & Land value & Changes of property or land value after project \\
\hline & Business profits & $\begin{array}{l}\text { Impacts of traffic improvement project to business patronage and profits within the } \\
\text { influence area }\end{array}$ \\
\hline
\end{tabular}

Fuzzy analytical hierarchy process (FAHP) is utilized to analyze uncertainty and variance due to stakeholder preferences on performance attributes. FAHP is used to establish the consensus weights among stakeholders concerning the performance attributes of a traffic improvement project, because it considers the relative importance or priority of the evaluation criteria and is both technically valid and practically useful in organizing and analyzing complex decisions. In addition, risk can be classified as objective or subjective [19]. Subjective risk is the major concern of decision-making because subjective risk is based on personal perception that may be related to the consequences of the failure and the degree of control of the situation [19]. FAHP takes subjective risk into account and is one of the best ways for deciding with a complex criteria structure in different levels [20, 21].

\subsection{Scaling with risk and uncertainty}

A single-attribute utility function is established to provide a dimensionless measurement of the performance MOEs of each attribute. All performance MOEs are expressed as a weighted dimensionless quantity to structure a single-attribute utility function with risk and uncertainty.

There are $m$ performance attributes defined for a project with $n$ alternatives $\left(A_{1}, A_{2}, \ldots, A_{n}\right)$. For one of the performance attributes $P_{j}(j=1,2, \ldots, m)$, the uncertainty range of the MOE $X$ used in quantifying the performance attributes $P_{j}$ for alternative $A_{i}$ can be denoted as $X \in\left[X_{\mathrm{L}}^{A_{i}}, X_{\mathrm{H}}^{A_{i}}\right]$, where $X_{\mathrm{L}}^{A_{i}}$ and $X_{\mathrm{H}}^{A_{i}}$ are lower and upper bound values of the MOE $X$ for alternative $A_{i}$. When $X_{\mathrm{L}}^{A_{i}}=X_{\mathrm{H}}^{A_{i}}$, the estimate of the MOE is a single value without uncertainty. The highest and lowest values of the MOE among all the alternatives $A_{1}, A_{2}, \ldots, A_{n}$ are denoted as $X_{\max }$ and $X_{\min }$, respectively. The estimates for MOE $X$ are then converted into dimensionless units by using a normalization process for the following three conditions:

(1) If a higher value of MOE represents more desirable performance, then by setting $u\left(X_{\max }\right)=1$ and $u\left(X_{\min }\right)=0$, the utility value is obtained as follows:

$u(X)=\left(\frac{X-X_{\min }}{X_{\max }-X_{\min }}\right)^{T}$. 
Table 2 Main indicators and measures of their uncertainties

\begin{tabular}{|c|c|c|c|}
\hline Attributes & MOEs & Methods of measurement & Suggested measurement of uncertainty \\
\hline Operation & Travel time savings & $\mathrm{HCM}$ and simulation & $\begin{array}{l}\text { Applying traffic volume in the peak and non-peak periods with } \\
\text { HCM or a simulation model }\end{array}$ \\
\hline Safety & Annual crash rate & HSM & $\begin{array}{l}\text { HSM directly provides estimates of standard error, variance or } \\
\text { other statistical reliability }\end{array}$ \\
\hline Energy & Fuel consumption & $\begin{array}{l}\text { Simulation and environmental } \\
\text { protection agency (EPA) regression } \\
\text { model }\end{array}$ & $\begin{array}{l}\text { Obtain the max and min outputs from the analysis model for } \\
\text { the best and worse conditions and then empirically select a } \\
\text { beta distribution }\end{array}$ \\
\hline Environment & $\begin{array}{l}\text { Vehicle emissions in } \\
\text { influence area }\end{array}$ & $\begin{array}{l}\text { Simulation and motor vehicle emission } \\
\text { simulator (MOVES) model }\end{array}$ & $\begin{array}{l}\text { Obtain the max and min outputs from the analysis model for } \\
\text { the best and worse conditions; then empirically select a beta } \\
\text { distribution }\end{array}$ \\
\hline Accessibility & $\begin{array}{l}\text { Business loss due to } \\
\text { reduction of } \\
\text { accessibility }\end{array}$ & $\begin{array}{l}\text { National cooperative highway research } \\
\text { program (NCHRP) } 420 \text { economic } \\
\text { impact model }\end{array}$ & $\begin{array}{l}\text { Range of potential business loss is given in NCHRP } 420 \\
\text { Economic Impact Model; Empirically select a beta } \\
\text { distribution }\end{array}$ \\
\hline Project cost & $\begin{array}{l}\text { Internal rate of } \\
\text { return }\end{array}$ & $\begin{array}{l}\text { Local specific data or AASHTO Red } \\
\text { Book }\end{array}$ & $\begin{array}{l}\text { Local or Red Book min-max range for IRR and then } \\
\text { empirically select a beta distribution }\end{array}$ \\
\hline
\end{tabular}

(2) If a lower value of MOE represents more desirable performance, then by setting $u\left(X_{\min }\right)=1$ and $u\left(X_{\max }\right)=0$, the utility value is obtained as follows:

$u(X)=\left(\frac{X_{\max }-X}{X_{\max }-X_{\min }}\right)^{T}$.

(3) If a middle-of-the-range value of MOE represents more desirable performance, then by setting $u\left(X_{\text {mid }}\right)=1$ and $u\left(X_{\max }\right)=u\left(X_{\min }\right)=0$, the utility value is obtained as follows:

$u(X)=\left\{\begin{array}{ll}\left(\frac{X-X_{\min }}{X_{\max }-X_{\min }}\right)^{T}, & \text { if }\left(X_{\min } \leq X<X_{\operatorname{mid}}\right) \\ \left(\frac{X_{\max }-X}{X_{\max }-X_{\min }}\right)^{T}, & \text { if }\left(X_{\operatorname{mid}} \leq X \leq X_{\max }\right)\end{array}\right.$.

In above equations, $T$ is the exponential parameter used to represent the nonlinear rate of change (increase or decrease) in normalized utility value. If there are $m$ different MOEs defined in the performance attributes $P_{i}$, then the single-attribute utility function of $P_{i}$ is written as follows:

$u\left(P_{i}\right)=\sum_{i=1}^{m}\left(D_{i} \times u\left(X_{i}\right)\right)^{\lambda}$,

where $D_{i}$ are the MOE weights defined using the Delphi method and $\lambda$ is the risk parameter. Risk parameters in single-attribute utility functions are used to describe the implications of subjective risk tolerance of stakeholders to the compromises among performance attitudes. A risktaking decision maker has a strictly convex utility function with $\lambda \in(1, \infty)$; A risk-neutral decision maker has a linear utility function with $\lambda=1$; and A risk-averse decision maker has a strictly concave utility function with $\lambda \in(0,1)$ $[21,22]$. Each attribute may be assigned a different risk parameter to reflect the sensitivity level to potential benefit loss in different performance attributes. Usually, the performance attributes that correspond to the primary objectives of the project should be assigned a risk-averse value. Performance attributes with moderate importance may use risk-neutral parameters. Decision maker attitudes on attributes that represent secondary or minor impacts of the project may be risk prone.

There may be a high level of uncertainty associated with some MOEs because the analysis tools and model inputs may have inherent variation and wide-ranging assumptions. Common methods for capturing uncertainty are sampling-based approach, uncertainty propagation, empirical selection and others [24]. The means selected for capturing uncertainties for traffic performance MOEs are summarized in Table 2.

A basic cost-benefit analysis also establishes a common monetized unit with concentration on the index of the economic efficiency by monetizing the performance MOEs to measure the costs and benefits in constant dollar value. However, many performance MOEs defined in this research such as air quality, noise and accessibility cannot be monetized due to a lack of reliable monetary values for them. Therefore, in the scaling stage of MAFU, a utility function was developed for any performance attribute by normalizing the values of MOEs into the $(0,1)$ space. The utility function provides a uniform and generalized scale and can integrate the risk behavior of the decision maker. In the following stage of combination, a system-wide multi-attribute utility function is developed by synthesizing single-attribute utility functions into a multi-attribute utility function. 


\subsection{Combination}

This stage combines single-attribute utility functions and develops a multiple-attribute utility function for all scaled and weighted performance attributes to determine the overall outcome of an alternative.

Because of the existence of possible correlations between some of the performance attributes, such as congested traffic (operational attribute) increases air pollution (environmental attribute), a multiplicative form was adopted to establish the multi-attribute utility functions that combine all the performance attributes for a project alternative, as shown in Eq. 5 [23]:

$$
\begin{aligned}
& U(P)=\sum_{i=1}^{n} k_{i} u\left(P_{i}\right)+k \sum_{\substack{i=1 \\
j>i}}^{n} k_{i} k_{j} u\left(P_{i}\right) u\left(P_{j}\right) \\
& +k^{2} \sum_{\substack{i=1 \\
j>i \\
e>j}}^{n} k_{i} k_{j} k_{e} u\left(P_{i}\right) u\left(P_{j}\right) u\left(P_{e}\right) \\
& +\cdots+k^{n-1} k_{1} k_{2} \cdots k_{n} u\left(P_{1}\right) u\left(P_{2}\right) \cdots u\left(P_{n}\right),
\end{aligned}
$$

where $U(P)$ is the multiplicative and combined utility function for a project, $u\left(P_{i}\right)\left(\right.$ or $\left.u\left(P_{j}\right), u\left(P_{e}\right), \ldots, u\left(P_{n}\right)\right)$ is the single utility function for the performance attribute
$P_{i}(i=1,2,3 \ldots j \ldots e \ldots n), k_{i}(i=1,2,3 \ldots j \ldots e \ldots n)$ is the positive weighting constant for adding the separate contribution of the attribute $i$ (i.e., the relative weights of performance attributes which were determined by FAHP in the weighting stage), and $k$ is a scaling constant and can be determined by examining the special case where $u\left(X_{i}\right)=1$ for all the attributes.

As a result, the utility equation can be further simplified as

$k+1=\prod_{i=1}^{n}\left(k k_{i}+1\right)$

where $k_{i}$ are the relative weights for each performance attribute from FAHP.

After the combined utility function is established, MCS is applied to capture the uncertainty level of outputs and develop a tradespace for alternative selection. $R$ Project for Statistical Computing [25] was utilized to conduct the simulation process because it has a fast execution speed and can work on objects of unlimited size and complexity [26]. The result of MCS is a probability distribution describing the range of output utility value. Because the utility function was used to combine and normalize all the performance attributes for project alternatives, the output utility value is confined in $[0,1]$.

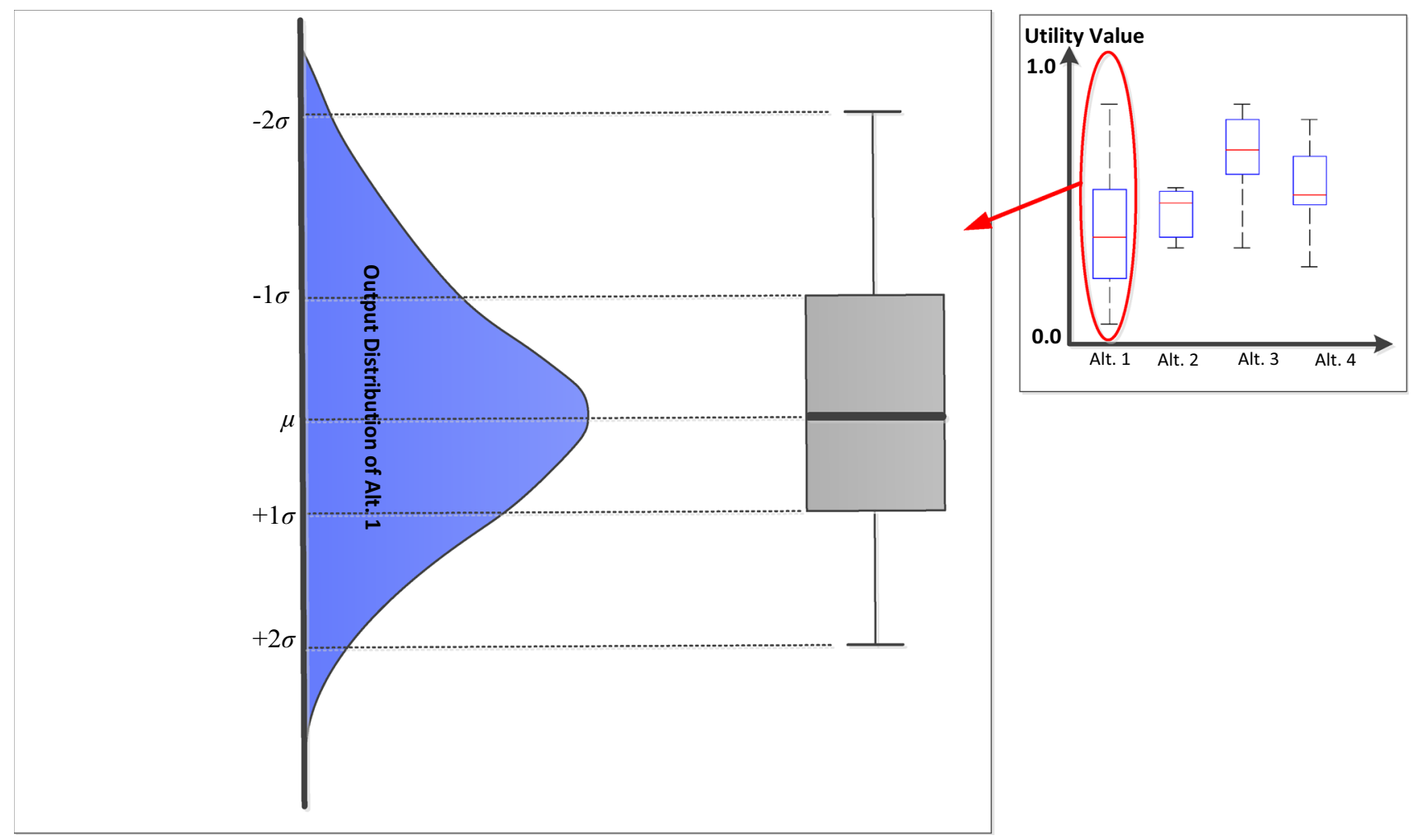

Fig. 3 Relation of the modified box plot to output probability density function 
The key statistic factors including expected values, variability and overall range of outputs are extracted from the simulation results and used in the following decision stage for alternative selection.

\subsection{Decision}

The "best" choice rarely achieves all the objectives and satisfies all the stakeholders. Therefore, the decision stage involves a trade-off analysis based on the utility values and their statistical information. Tradespace is the solution space. The tradespace is presented as a box plot including the information of expected value, variance, and upper and lower boundary of value range, to explicitly describe the trade-offs between every alternative. Figure 3 indicates the relation of the modified box plot to a probability density function of an output distribution of an alternative, where $\sigma$ is standard deviation and $\mu$ is mean.

The selection of the best alternative may be based on the comparison between performance benefit and project cost. Performance benefits refer to the utility values generated by the MCS from the multi-attribute utility model. The project cost includes initial costs, operation and maintenance costs and other direct or indirect costs for each proposed alternative. If the uncertainty in project costs or discount rates are concerns of the decision makers, or if the minimization of project cost is one of the primary project objectives, then the project cost of each alternative can be treated as one of the performance attributes. In this case, the overall utility values are used for selecting the best alternative.

A concern of using MCS to create a stochastic model is the efficiency of the simulation outputs, especially when multiple objectives and variables are involved. Every output from the proposed method is associated with a variance, which may limit the precision of the simulation results. If the uncertainty ranges associated with performance MOEs are wide, then the variance of the utility index assigned to each alternative may be so large that it covers the entire set of all possible values. To make a simulation statistically efficient and improve the precision of outputs, if necessary, variance reduction techniques can

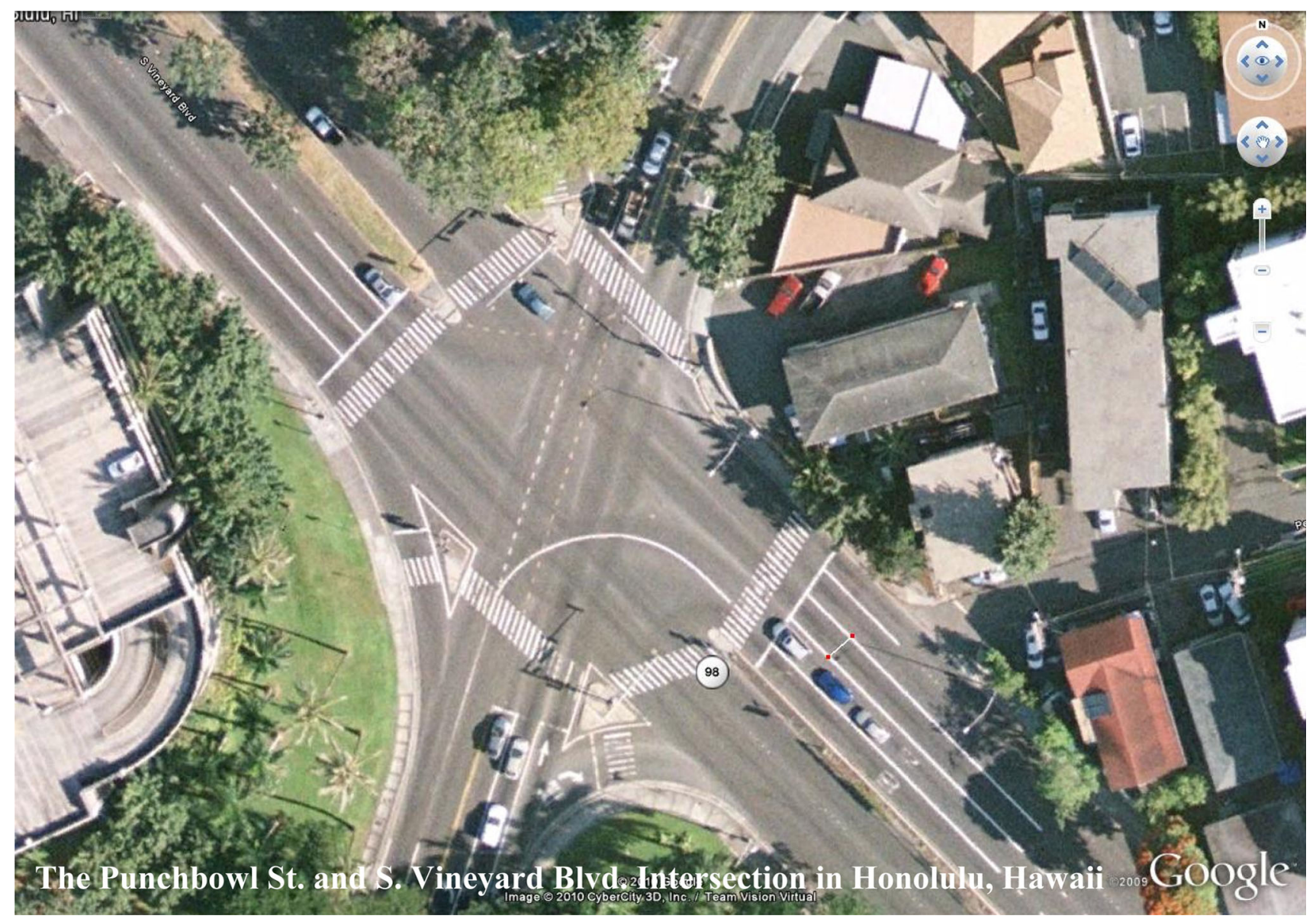

Fig. 4 Google map of study intersection prototype 
be deployed to obtain smaller confidence intervals for the outputs [24].

\section{Case study}

This case study demonstrates the use of the proposed comprehensive evaluation and decision-making methodology. The prototype of study intersection is a congested intersection near downtown Honolulu (See Fig. 4). The subject intersection experiences serious congestion during morning and afternoon peaks largely because both $\mathrm{N}-\mathrm{S}$ and E-W directions connect downtown with a freeway. The surrounding road network provides short and convenient rerouting paths. Abutting land uses include residences, governmental buildings, an elementary school, businesses and a large hospital; they generate moderately high pedestrian volumes. The proposed traffic project includes three alternatives: do-nothing (DN), left-turn prohibition (LTP) and a low-clearance underpass (LCUP).

Four performance attributes were used in this evaluation including operations, safety, environment and energy. The performance analysis results shown in Table 3 were obtained from Levels 1 and 2 (Fig. 1). Specifically, MOEs for traffic operations, environment and energy attributes were quantified using the AIMSUN traffic network simulator [27]. Annual accident rates and fatality rates were estimated using accident prediction models in HSM and adjusted for urban signalized 4-leg intersection based on the statistical models developed by the Midwest Research Institute [28].

The stakeholders defined for this project include intersection users who use this intersection, residents who live close to the intersection and the intersection owner (Hawaii State DOT).

The inputs of weights and risk parameter assignments for the four performance attributes are summarized in Table 4. There are multiple MOEs for safety and environment. The Delphi method can yield weights for multiple MOEs. The Delphi process would run as many times as necessary to reach the agreements on the weights among the stakeholder groups. During this process, the variation of the answers from different groups will decrease and the groups will converge toward one outcome. However, an expert group was not used in this case study due to timing and budget constraints. Weights were assigned to the MOEs based on the following data:

- Most states use the costs associated with accident severity as the weights to calculate the level of safety [29].

- According to the accident costs in UBA (shown in Table 4), the normalized weights assigned to PDO/

Table 3 Performance analysis results of LTP and LCUP

\begin{tabular}{|c|c|c|c|c|c|c|c|c|c|}
\hline \multirow[t]{2}{*}{ Attributes } & \multirow[t]{2}{*}{ MOEs } & \multicolumn{2}{|l|}{$\mathrm{DN}$} & \multicolumn{3}{|l|}{ LTP } & \multicolumn{3}{|c|}{ LCUP } \\
\hline & & AM & PM & $\mathrm{AM}$ & PM & Annual change $^{a}$ & $\mathrm{AM}$ & PM & Annual change ${ }^{\mathrm{a}}$ \\
\hline Traffic operations & Traffic delay (s/veh) & 83.5 & 75.3 & 40.2 & 56.4 & 31,100 & 50.6 & 33.1 & 37,550 \\
\hline \multirow[t]{2}{*}{ Traffic safety } & PDO and injury accidents & 10.4 & & 5.9 & & 4.5 & 7.7 & & 2.7 \\
\hline & Annual fatal accidents & 1.3 & & 0.4 & & 0.9 & 0.6 & & 0.7 \\
\hline \multirow[t]{2}{*}{ Environment } & $\mathrm{NO}_{x}$ pollutant $(\mathrm{kg})$ & 1.4 & 0.6 & 1.1 & 0.6 & 203.1 & 0.6 & 0.6 & 464.2 \\
\hline & $\mathrm{CO}_{2}(\mathrm{~kg})$ & 983.7 & 917.6 & 790.6 & 792.5 & 159,100 & 404.7 & 420.6 & 538,000 \\
\hline Energy & Fuel (U.S. gal) & 109.8 & 44.8 & 85.6 & 41.8 & 13,600 & 35.5 & 38.4 & 40,350 \\
\hline
\end{tabular}

${ }^{a}$ The AM and PM peak hour estimates were expanded to annual estimates by multiplying by a daily expansion factor of 2.0 and by a yearly expansion factor of 250, except for traffic safety MOEs which are annual rates. $\mathrm{CO}_{2}$ is a greenhouse gas

Table 4 Summary of weights and risk parameter assignments

\begin{tabular}{lllll}
\hline Attributes & MOEs & $\begin{array}{l}\text { MOE weights } W_{a} \\
\text { (Delphi) }\end{array}$ & $\begin{array}{l}\text { Attribute weight } k_{i} \\
\text { (FAHP) }\end{array}$ & Risk parameter $\gamma$ \\
\hline Traffic operation & Traffic delay (s/veh) & 1 & 0.35 & 0.5 \\
Traffic safety & PDO and injury accidents & 0.03 & 0.58 & 0.5 \\
& Annual fatal accidents & 0.97 & & 0.04 \\
Environment & NO $x$ pollutant (kg) & 0.8 & & 1.0 \\
Greenhouse gas (kg) & 0.2 & 0.03 & 1.0 \\
\hline
\end{tabular}


Table 5 Normalized uncertainty ranges of performance attributes

\begin{tabular}{|c|c|c|c|c|c|c|c|}
\hline \multirow[t]{2}{*}{ Attributes } & \multirow[t]{2}{*}{ MOEs } & \multicolumn{2}{|l|}{ DN } & \multicolumn{2}{|l|}{ LTP } & \multicolumn{2}{|l|}{ LCUP } \\
\hline & & AM & PM & $\mathrm{AM}$ & PM & $\mathrm{AM}$ & PM \\
\hline Traffic operation & Traffic delay (s/veh) & $(0,0.38)$ & $(0.13,0.46)$ & $(0.60,0.89)$ & $(0.33,0.75)$ & $(0.42,0.81)$ & $(0.68,1)$ \\
\hline \multirow[t]{2}{*}{ Traffic safety } & PDO/injury accidents & $(0,0.08)$ & & $(0.92,1)$ & & $(0.55,0.63)$ & \\
\hline & Annual fatal accidents & $(0,0.15)$ & & $(0.85,1)$ & & $(0.66,0.81)$ & \\
\hline \multirow[t]{2}{*}{ Environment } & $\mathrm{NO}_{x}$ pollutant $(\mathrm{kg})$ & $(0,0.45)$ & $(0.73,0.94)$ & $(0.31,0.66)$ & $(0.81,0.99)$ & $(0.82,1)$ & $(0.81,0.99)$ \\
\hline & Greenhouse gas (kg) & $(0,0.46)$ & $(0.09,0.52)$ & $(0.27,0.64)$ & $(0.27,0.64)$ & $(0.81,1)$ & $(0.79,0.99)$ \\
\hline Energy & Fuel (U.S. gal) & $(0,0.42)$ & $(0.75,0.93)$ & $(0.28,0.61)$ & $(0.79,0.95)$ & $(0.86,1)$ & $(0.83,0.98)$ \\
\hline
\end{tabular}

injury accident rates and fatal accident rates are 0.03 and 0.97 [16].

- According to the EPA's 2012 Environmental Fact Sheet [30], $\mathrm{NO}_{x}$ is one of the six criteria air pollutants. $\mathrm{CO}_{2}$ is not considered as air pollutant but is an environmental concern because of its global warming potential. A higher weight (0.8) was assigned to $\mathrm{NO}_{x}$ and a lower weight $(0.2)$ was assigned to $\mathrm{CO}_{2}$.

FAHP was used to establish the weights for the performance attributes. Traffic safety has the highest weighting score followed by traffic operations. Environment and energy are secondary considerations of stakeholders and were weighed using a lower score.

The estimates of performance MOEs contain a certain amount of uncertainty. The uncertainty of each attribute is summarized in Table 5. Uncertainty in traffic operations and traffic safety was assumed to be a normal distribution and was determined based on: (i) AIMSUN output of traffic delays along with their standard derivation and (ii) the standard error from HSM traffic accident prediction models. Measurement of environment and energy attributes involves a quasi-linear relation with the traffic simulation outputs. For simplicity, they were uniformly distributed within a range of $\pm 20 \%$. The utility functions for each attribute were established as

$u\left(P_{i}\right)=\left[\sum_{i=1}^{n} w_{a} w_{b} u\left(X_{i}\right)\right]^{\lambda}$,

where $u\left(X_{i}\right)$ is the normalized utility value with uncertainty of MOE $X_{i} ; W_{a}$ is the weight score for MOE $X_{i}$ (Table 4); and $W_{b}$ is the weight for AM and PM peak period (in this case, $W_{b}=0.5$ ).

The single-attribute utility functions must be combined to develop a system-wide multiple-attribute function. In this case study, the multi-attribute function is written as follows:

$$
\begin{aligned}
U(P)= & {\left[\sum_{i=1}^{4} k_{i} u\left(P_{i}\right)\right] \cdot U_{\text {adj }} \cdot N\left(x_{\text {cost }}\right) } \\
= & {\left[0.35 u\left(P_{1}\right)+0.58 u\left(P_{2}\right)+0.04 u\left(P_{3}\right)\right.} \\
& \left.+0.03 u\left(P_{4}\right)\right] \cdot U_{\text {adj }} \cdot N\left(x_{\text {cost }}\right),
\end{aligned}
$$

where $k_{i}$ is the attribute weight obtained by FAHP (Table 4); $P_{1}, P_{2}, P_{3}$ and $P_{4}$ stand for the performance attributes of traffic operation, traffic safety, environment and energy, respectively; $N\left(x_{\text {cost }}\right)$ is a normal distribution utility function of the project cost index $x_{\text {cost }}$; and $U_{\text {adj }}$ is an adjustment factor to reflect the ability of an alternative to accommodate future traffic growth.

Lower cost is given a higher utility index. The project cost of do-nothing is $\$ 0$ so its utility value is 1.00 . Low, medium and high project cost for both LTP and LCUP estimated in the Level 1 planning level analysis [17] were normalized before using them in the utility functions. The normalized uncertainty range of cost is $(0.68,0.85)$ for LTP and $(0,0.54)$ for LCUP. The uncertainty of project costs is assumed to be a normal distribution with a mean that is equal to the medium costs. The risk parameter of $1 / 2$ (risk averse) is assigned to project cost utility function, because cost is always a risk-sensitive factor in transportation projects.

Based on the historical traffic counts, the traffic growth rate in the periphery of downtown Honolulu where the subject intersection is located is about $1.2 \%$ per year (estimated annual growth rate). This case study examines the ability of each alternative to accommodate traffic growth for at least 10 years into the future. The normalized uncertainty range of the adjustment index is $(0.00,0.10)$ for do-nothing, which means the current intersection condition can accommodate none or very little traffic growth. The range is $(0.12,0.20)$ for LTP and $(0.93,1.00)$ for LCUP. The ranges were estimated using the ratio of remaining capacity of each alternative over the forecasting demand growth in 10 years. 
Table 6 Expected utility index and standard derivation of alternatives

\begin{tabular}{|c|c|c|c|c|c|c|c|c|c|}
\hline \multirow[t]{2}{*}{ Analysis scenario } & \multicolumn{3}{|l|}{ DN } & \multicolumn{3}{|l|}{ LTP } & \multicolumn{3}{|l|}{ LCUP } \\
\hline & $\begin{array}{l}\text { Expected } \\
\text { utility }\end{array}$ & $\begin{array}{l}\text { Standard } \\
\text { derivation }\end{array}$ & $D_{i}$ & $\begin{array}{l}\text { Expected } \\
\text { utility }\end{array}$ & $\begin{array}{l}\text { Standard } \\
\text { derivation }\end{array}$ & $D_{i}$ & $\begin{array}{l}\text { Expected } \\
\text { utility }\end{array}$ & $\begin{array}{l}\text { Standard } \\
\text { derivation }\end{array}$ & $D_{i}$ \\
\hline $\begin{array}{l}\text { Without risk } \\
\text { parameter }\end{array}$ & 0.008 & 0.005 & 0.997 & 0.098 & 0.016 & 0.918 & 0.187 & 0.030 & 0.843 \\
\hline $\begin{array}{l}\text { With risk } \\
\text { parameter }\end{array}$ & 0.002 & 0.001 & 0.999 & 0.026 & 0.004 & 0.978 & 0.051 & 0.007 & 0.956 \\
\hline
\end{tabular}

Data in bold indicates the lowest standard derivation and the highest expected utility among all three alternatives

System-wide utility functions were programmed into $R$ Project to conduct the MCS. This case study used 10,000 replications, and the results are shown in Table 6. The expected utility and standard derivation are estimated for each alternative for two combinations: with and without risk parameters. The results indicate that LCUP has the highest expected utility values and highest standard derivation, and DN has the lowest expected utility values and lowest standard derivation. The results are logical: DN is the most conservative option with little uncertainty, but is unable to provide any benefits other than minimal direct cost.

As shown in Table 6, the involvement of risk parameters does not change the order of ranking based on expected value or variance, but it causes a decrease in the variance of the estimate, because risk parameters reflect the sensitivity to marginal loss in the benefits for each performance attribute.

This case study was developed for demonstration purposes only. A relatively small number of stakeholders and performance attributes were defined and the uncertainties associated with selected MOEs were reasonably defined; therefore, the reliability of model outputs is acceptable and no variance reduction process is necessary.

These outputs of MAFU can be used to evaluate the corresponding outcomes from MAFU against a traditional cost-benefit analysis. These are shown in Fig. 5 where Scenario 1 is an application of a classic cost-benefit analysis to make decision based on operational and safety estimates with static HCM and HSM models [17] and Scenario 2 is the case study analysis with MAFU as detailed above. The comparison between the MAFU and traditional method shows that both methods may generate some ranking of project alternative based on the average utility value (i.e., the middle bar of the box plot), but the traditional method generates an overlapping confidence interval and min-max ranges among the project alternatives, which complicates the decision marking and alternative selection process.

In addition, the tradespace depiction reveals that the traditional cost-benefit analysis produced the maximum variance of expected utility and risk, whereas MAFU

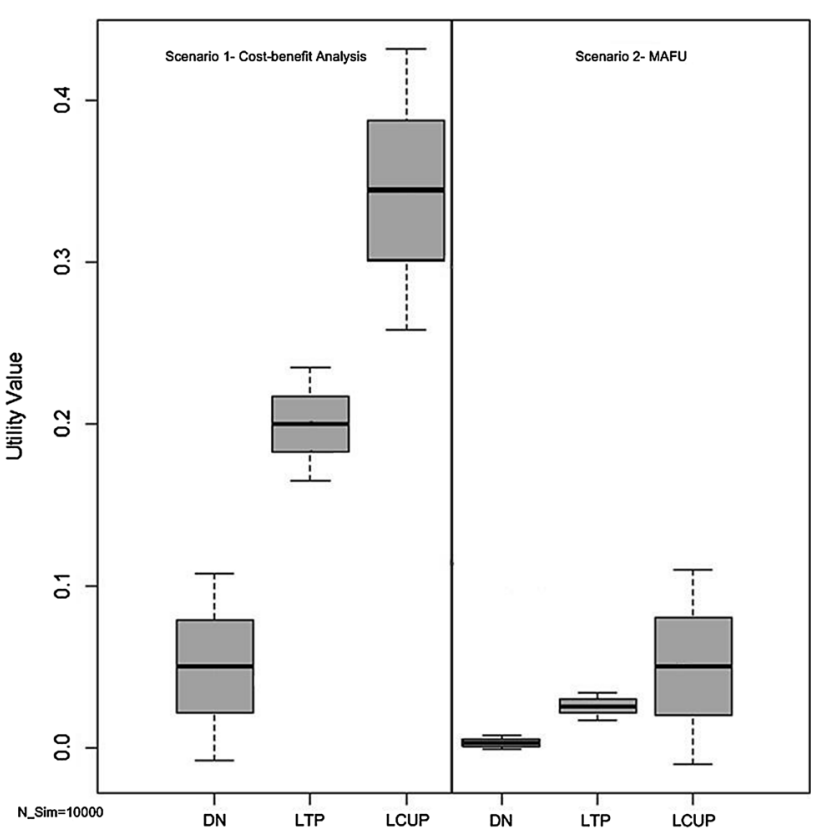

Fig. 5 Sample tradespace of conventional cost-benefit analysis and MAFU. Note: $D N$ is do-nothing; $L T P$ is left-turn prohibition; $L C U P$ is low-clearance underpass, $\quad N \_\operatorname{Sim}=10,000$ is the number of the Monte Carlo Simulation replications

produced the smallest variance. Without considering stakeholder preferences, the uncertainty associated with performance such as operation and safety is unrestricted and cumulative as shown in Scenario 1. The results clearly suggest that a reliable multi-attribute evaluation of a complex traffic project should not be made with conventional cost-benefit analysis alone, because the proposed MAFU method provided more robust outputs under a complex decision-making environment associated with multiple risk factors and stakeholders.

\section{Conclusion}

This research arose from the challenges in decision-making for traffic improvement projects. Some traffic projects have substantial impacts on the surrounding community. The 
projects involve multiple stakeholders with conflicting interests. The proposed method enables robust decisions for alternative selection by making use of all available information, managing conflicting interests and presenting performance targets and trade-offs.

MAFU, the multiple-attribute evaluation method under fuzziness and uncertainty integrates operations, safety, economic, energy, environment, stakeholder objectives and uncertainty analysis into one decision-making model. MAFU establishes a fuzzy set for including stakeholder preferences, develops system-wide multiplicative multiattribute utility functions for each alternative and generates a tradespace for alternative selection. MAFU is a rational, comprehensive and well-defined decision-making system that incorporates complex trade-offs and uncertainty analysis, but results in relatively simple and visual selection scenarios within specific risk and variance categories.

Traditional evaluation methods, such as CBA, typically are aggregated approaches assuming a broad view of net benefits over all affected stakeholders and interests and exclude the trade-offs between stakeholders and performance uncertainties, which may result in inaccurate decision-making and generate enduring bias, especially for a large infrastructure projects with high risk of cost overruns, uncertain return period and conflicting interests. Therefore, a reliable multi-attribute and multi-stakeholder evaluation should not be made with conventional CBA alone, but with a final comprehensive evaluation method, like MAFU, which involves multiple dimensions of performance measurement to capture and disaggregate tangible and intangible attributes of individual stakeholders.

The MAFU is designed to be a new insight for transportation decision-making through the visual and complex preference trade-offs, and criteria uncertainty and an openended approach, which can integrate additional evaluation criteria and performance attributes as needed. With adjustments, MAFU can become a generic tool applicable to other engineering projects (e.g., selection of a given capacity electric power plant among several competing technologies.) In general, MAFU is more appropriate for large traffic and transportation projects associated with significant capital investment, and high levels of uncertainty and stakeholder involvement. After all, the key criteria in determining the need for the MAFU approach are (1) considerable risk or fuzziness regarding the estimation of performance indicators; (2) multiple stakeholders with conflicting interests in their expectations for a proposed project; and (3) changes in one or some underlying assumptions can result in a significant variation in the ranking of alternatives.

Open Access This article is distributed under the terms of the Creative Commons Attribution 4.0 International License (http:// creativecommons.org/licenses/by/4.0/), which permits unrestricted use, distribution, and reproduction in any medium, provided you give appropriate credit to the original author(s) and the source, provide a link to the Creative Commons license, and indicate if changes were made.

\section{References}

1. FHWA (2008) Economic analysis primer: benefit-cost analysis. FHWA-IF-03-032, Aug 2008

2. Nickel J, Ross AM, Rhodes DH (2009) Comparison of project evaluation using cost-benefit analysis and multi-attribute tradespace exploration in the transportation domain. In: Second international symposium on engineering systems, MIT, Cambridge, Massachusetts, June 15-17 2009

3. Kissi Dompere K (2004) Cost-benefit analysis and the theory of fuzzy decisions: identification and measurement theory, 1st edn. Springer, New York

4. FHWA (2014) Surface transportation efficiency analysis model. https://www.fhwa.dot.gov/steam. Accessed July 222014

5. Bayarri M, Berger J, Molina G, et al (2003) Assessing uncertainties in traffic simulation: a key component in model calibration and validation. Technical Report Number 137, National Institute of Statistical Sciences, Research Triangle Park, NC, July

6. Ji XJ, Prevedouros PD (2006) Probabilistic analysis of HCM delay for signalized intersections. Transportation Research Record, No. 1988, pp 67-75, TRB, NRC, Washington, D.C.

7. Li Z, Sinha KC (2004) Methodology for the development of a highway asset management system for Indiana. Publication FHWA/IN/JTRP-2003/21. Joint Transportation Research Program, Indiana DOT and Purdue University, West Lafayette, Indiana. doi: 10.5703/1288284313267

8. Zimmermann HJ (1987) Fuzzy sets, decision-making and expert systems, 1st edn. Springer, New York

9. Baas SM, Kwakernaak H (1977) Rating and ranking of multipleaspect alternatives using fuzzy sets. Automatica 13(1):47-51

10. Arslan T (2008) A hybrid model of fuzzy and AHP for handling public assessments on transportation projects. Transportation 36(1):97

11. Bandte O (2000) A probabilistic multi-criteria decision-making technique for conceptual and preliminary aerospace systems design. PhD Dissertation, Georgia Institute of Technology, Sept 2000

12. Ross AM, Hastings DE, Warmkessel JM (2004) Multi-attribute tradespace exploration as front end for effective space system design. J Spacecr Rockets 41(1):20-28

13. Nickel J (2010) Using multi-attribute tradespace exploration for the architecting and design of transportation systems. PhD Dissertation, Massachusetts Institute of Technology

14. TRB (2011) The highway capacity manual, 5th edn. NRC, Washington, D.C.

15. AASHTO (2001) Highway safety manual, 1st edn. AASHTO, Washington, D.C.

16. AASHTO (2010) A manual of user benefit analysis for highways, 3rd edn. AASHTO, Washington, D.C.

17. Yu X, Prevedouros PD (2013) Left turn prohibition and partial grade separation for signalized intersections. J Transp Eng 139(4):399-406

18. Skulmoski G, Hartman FT, Krahn J (2007) The Delphi method for graduate research. J Inf Technol Educ 6:1-21

19. FHWA (1998) Life-cycle cost analysis in pavement design-in search of better investment decisions. U.S. DOT

20. Özdağoğlu A, Özdağoğlu G (2007) Comparison of AHP and fuzzy AHP for the multicriteria decision-making processes with 
linguistic evaluations. İstanbul Ticaret Üniversitesi Fen Bilimleri Dergisi Y1l: 6 Say1:11Bahar 2007/1 s. pp 65-85

21. Banai R (2006) Public transportation decision-making: a case analysis of the memphis light rail corridor and route selection with analytic hierarchy process. J Public Transp 9(2):1-24

22. Sinha KC, Labi S (2007) Transportation decision making: principles of project evaluation and programming, 1st edn. Wiley, Hoboken

23. Keeney RL, Raiffa H (1997) Decisions with multiple objectivespreferences and value tradeoffs. Cambridge University Press, Cambridge

24. Yu X (Alyx) (2012) Comprehensive method for evaluating signalized intersection treatments: left turn prohibition and partial grade separation. $\mathrm{PhD}$ dissertation, University of Hawaii, Dec

25. Venables WN, Smith DM, the R Development Core Team (2011) An introduction to $\mathrm{R}$, notes on $\mathrm{R}$ : a programming environment for data analysis and graphics, version 2.14.1
26. Rossiter DG (2014) Introduction to the R project for statistical computing for use at ITC, International Institute for Geo-information Science \& Earth Observation (ITC), Enschede (NL). http://www.itc.nl/personal/rossiter

27. Transport Simulation Systems (2014) Aimsum microscopic traffic simulator. http://www.aimsun.com. Accessed July 222014

28. Bauer KM, Harwood DW (2000) Statistical models of at-grade intersection accidents-addendum. Publication No. FHWA-RD99-094, Midwest Research Institute

29. FHWA (2011) Highway safety improvement program manual. Highway safety improvement program. Retrieved on Sept 17 2013. http://safety.fhwa.dot.gov/hsip/resources/fhwasa09029/ sec2.cfm

30. EPA (2012) Environmental fact sheet 2012. Office of Mobile Sources, May 2012 